\title{
Identification and role of ionizing functional groups at the active center of Rhodotorula gracilis D-amino acid oxidase
}

\author{
Loredano Pollegioni ${ }^{\mathrm{a}, *}$, Christopher M. Harris ${ }^{\mathrm{a}, 1}$, Gianluca Molla ${ }^{\mathrm{a}}$, Mirella S. Pilone ${ }^{\mathrm{a}}$, \\ Sandro Ghisla ${ }^{\mathrm{b}}$ \\ a Department of Structural and Functional Biology, University of Insubria, via J.H. Dunant 3, 21100 Varese, Italy \\ ${ }^{\mathrm{b}}$ Faculty of Biology, University of Konstanz, P.O. Box 5560-M644, D-78434 Konstanz, Germany
}

\begin{abstract}
D-Amino acid oxidase (DAAO) is a flavoprotein oxidase that catalyzes the oxidation of amino acids and produces ketoacids and $\mathrm{H}_{2} \mathrm{O}_{2}$. The rate of product release from reduced DAAO from Rhodotorula gracilis is $\mathrm{pH}$ dependent and reflects a $\mathrm{p} K_{\mathrm{a}}$ of $\sim 9.3$. Binding of benzoate and 3,3,3-trifluoro-D-alanine to wild-type and Y238F-DAAO is also $\mathrm{pH}$ dependent $\left(\mathrm{p} K_{\mathrm{a}}=9.8 \pm 0.1\right.$ and $9.05 \pm 0.1$, respectively for benzoate binding). However, binding of benzoate to Y223F-DAAO is $\mathrm{pH}$ independent, indicating the $\mathrm{p} K_{\mathrm{a}}$ is due to $\mathrm{Y223}-\mathrm{OH}$. This latter residue is thus involved in substrate binding, and probably is the group that governs product release. In contrast to this, the second active site tyrosine, Y238, has little influence on ligand binding.
\end{abstract}

Key words: D-Amino acid oxidase; Flavoprotein; $\mathrm{pH}$ effect; Ligand binding; Ionization; Catalytic mechanism

\section{Introduction}

D-Amino acid oxidase (DAAO; EC 1.4.3.3) is a model enzyme of the dehydrogenase-oxidase class of flavoproteins [1] and has, thus, been the subject of a series of kinetic, mechanistic, and structural studies. DAAO catalyzes the dehydrogenation of D-amino acids to the corresponding imino acids (subsequently hydrolyzed to $\alpha$-ketoacids and ammonia) with concomitant reduction of the FAD cofactor [2,3]. The reduced flavin is then reoxidized by $\mathrm{O}_{2}$ to yield $\mathrm{H}_{2} \mathrm{O}_{2}$. DAAO was first isolated as a homogeneous flavoprotein from pig kidney (pkDAAO) and later from the yeasts Rhodotorula gracilis (RgDAAO) and Trigonopsis variabilis (TvDAAO) [2,3]. All enzymes show a sequential kinetic mechanism with substrates containing neutral side chains, and comparison of primary structures of DAAO from various sources indicate high conservation of key regions [4].

\footnotetext{
*Corresponding author. Fax: (39)-332-421500.

E-mail address: loredano.pollegioni@uninsubria.it (L. Pollegioni).

1 Present address: Department of Chemistry, University of Utah, Salt Lake City, UT 84112, USA.
}

Abbreviations: RgDAAO, Rhodotorula gracilis D-amino acid oxidase; pkDAAO, pig kidney D-amino acid oxidase; $\mathrm{CF}_{3}$-alanine, 3,3,3-trifluoro-alanine; Bz, benzoate
The crystal structures of RgDAAO in complex with D-alanine and with D-3,3,3-trifluoro $\left(\mathrm{CF}_{3}\right)$-alanine [5] show how the ligand is anchored to the protein (Fig. 1). This involves two strong H-bonds with the substrate $\alpha \mathrm{NH}_{2}$, with $\mathrm{S} 335=\mathrm{O}$ and with $\mathrm{H}_{2} \mathrm{O} 72$, and a salt bridge between the amino acid carboxylate and R285. In addition, the Y223-OH and Y238-OH form $\mathrm{H}$-bonds to one of the carboxylate oxygens. The biochemical properties of Y223F and Y238F RgDAAO mutants are very close to those of wild-type protein [6,7]: both mutants are active and their rates of reduction by $D$-alanine are slightly faster than that of wild-type enzyme. However, both tyrosine mutants show a higher $K_{\mathrm{m}}$ for D-alanine and a $\sim 5$ fold higher $K_{\mathrm{d}}$ for benzoate $(\mathrm{Bz})$ binding at $\mathrm{pH} 8.5$ [6,7].

Recently, a hydride transfer mechanism was proposed by Mattevi's and by our group for DAAO [8,9]. This is based on different, but complementary, approaches. The 3D-structures $[5,8,10]$ and results from site-directed mutagenesis $[6,7,11,12]$ with pk- and RgDAAOs highlight the absence of any functional group that might play a role in acid/base catalysis and, thus, in abstraction of the substrate $\alpha \mathrm{C}-\mathrm{H}$ as required by a 'carbanion mechanism'. The rate of flavin reduction of RgDAAO reaction with $\mathrm{D}$-alanine and $\mathrm{D}$-asparagine attain plateaus at high and low $\mathrm{pH}$ reflecting two apparent $\mathrm{p} K_{\mathrm{a}} \mathrm{s}$ at $\sim 6$ and $\sim 8$, also consistent with the absence of base catalysts [13]. The apparent $\mathrm{p} K_{\mathrm{a}} \sim 8$ is attributed to the interplay of kinetic rates and to the microscopic ionization of the bound substrate $\alpha$-amino group [13]. These results concord with linear free energy relationships and kinetic isotope effects (KIEs) obtained with TvDAAO [9]. The aim of the present work was the characterization and identification of the ionizations that are important for ligand binding/release and, specifically, the elucidation of the roles of Y223 and Y238 therein.

\section{Materials and methods}

\subsection{Materials}

$\mathrm{D}, \mathrm{L}-\mathrm{CF}_{3}$-alanine was purchased from $\mathrm{ABCR} \mathrm{GmbH}$ (Germany). Recombinant RgDAAO was expressed and purified from Escherichia coli cells [3]. Production and general properties of Y223F and Y238F RgDAAOs were described elsewhere [6,7]. In order to minimize artefacts arising from changes in buffer composition, $\mathrm{pH}$ effects were performed in a poly-buffer containing $15 \mathrm{mM} \mathrm{H}_{3} \mathrm{PO}_{4}, 15 \mathrm{mM}$ Tris, $15 \mathrm{mM} \mathrm{Na}_{2} \mathrm{CO}_{3}, 250 \mathrm{mM} \mathrm{KCl}, 1 \mathrm{mM}$ 2-mercaptoethanol, and $1 \%$ glycerol. The high $\mathrm{KCl}$ was used to buffer against minor changes in ionic strength at different $\mathrm{pH}$ values. These buffers were adjusted to the appropriate $\mathrm{pH}$ with $\mathrm{HCl}$ or $\mathrm{KOH}$. 


\subsection{Ligand binding and kinetic measurements}

Dissociation constants $\left(K_{\mathrm{d}}\right)$ for binding of $\mathrm{Bz}$ and $\mathrm{CF}_{3}$-alanine were determined spectrophotometrically at $15^{\circ} \mathrm{C}$. For Bz binding, samples were $1.0 \mathrm{ml}$ and contained $\sim 15 \mu \mathrm{M}$ RgDAAO. $1-10 \mu \mathrm{l}$ volumes of concentrated $\mathrm{Bz}$ solutions were added sequentially, and spectra were recorded. Plots of $\Delta A_{497 \mathrm{~nm}}$ as a function of Bz were fit to Eq. 1 [14] to obtain $K_{\mathrm{d}}$ :

$\Delta A=\Delta A_{\text {tot }}[\mathrm{Bz}] /\left(K_{\mathrm{d}}+[\mathrm{Bz}]\right)$

Binding studies with $\mathrm{CF}_{3}$-alanine were performed with $0.4 \mathrm{ml}$ samples in $0.5 \mathrm{ml}$ cuvettes and at $\operatorname{RgDAAO} \sim 24 \mu \mathrm{M}$. Kinetic data were acquired with a stopped-flow instrument as described previously [13] and at $25^{\circ} \mathrm{C}$.

\subsection{Interpretation of $\mathrm{pH}$ effects}

The effect of $\mathrm{pH}$ on formation of enzyme-ligand complexes can be described according to the conventions of Dixon [15] where Eq. 2 describes the effect on $K_{\mathrm{d}}$ for a single ionization such that the ligand binds only to the protonated form:

$\mathrm{p}\left(K_{\mathrm{d}}\right)=\mathrm{p}\left(K_{\mathrm{d}, \text { acidic }}\right)-\log \left(1+10^{\mathrm{pH}-\mathrm{p} K_{\mathrm{a}}}\right)$

Each curvature on the $\mathrm{p} K_{\mathrm{d}}$ vs. $\mathrm{pH}$ plot corresponds to an ionization. Downward curvature indicates the ionization occurs in the free $\mathrm{E}$ or $\mathrm{L}\left(\mathrm{p} K_{\mathrm{a}}, \mathrm{E}\right.$ or $\left.\mathrm{L}\right)$, and upward curvature indicates ionization of the $\mathrm{E} \sim \mathrm{L}$ complex $\left(\mathrm{p} K_{\mathrm{a}}, \mathrm{E} \sim \mathrm{L}\right)[15]$

\section{Results}

\section{1. pH dependence of the rate of product dissociation from the reduced enzyme}

The $\mathrm{pH}$ dependence of the reductive half-reaction of oxidized RgDAAO with excess D-alanine has been recently described [13]. Values for the rate of product release, $k_{\mathrm{p}}$ in Eq. 3 below, were reported at three $\mathrm{pH}$ values $(\mathrm{pH} 6,8,10)$ as obtained by procedures described in that paper. In Fig. 2, inset, product release $\left(k_{\mathrm{p}}\right)$ corresponds to the absorbance decrease that follows the initial flavin reduction step $\left(k_{2}\right.$, the increase finished by $0.1 \mathrm{~s}$ ).

$\mathrm{E}_{\mathrm{ox}}+\mathrm{S} \underset{k_{-1}}{\stackrel{k_{1}}{\rightleftharpoons}} \mathrm{E}_{\mathrm{ox}} \sim \mathrm{S} \underset{k_{-2}}{\stackrel{k_{2}}{\rightleftharpoons}} \mathrm{E}_{\mathrm{red}} \sim \mathrm{P} \underset{k_{-\mathrm{p}}}{\stackrel{k_{\mathrm{p}}}{\rightleftharpoons}} \mathrm{E}_{\mathrm{red}}+\mathrm{P}$

We now report the $\mathrm{pH}$ dependence of $k_{\mathrm{p}}$ over the measurable $\mathrm{pH}$ range in $\mathrm{H}_{2} \mathrm{O}$ and in $\mathrm{D}_{2} \mathrm{O}$ in order to correlate it with processes involving ligand binding. The rate of product release is fairly constant at low $\mathrm{pH}$ and increases above $\mathrm{pH}$ 9, reflecting a $\mathrm{p} K_{\mathrm{a}}=9.3 \pm 0.2$ (Fig. 2) for both $\mathrm{H}_{2} \mathrm{O}$ and $\mathrm{D}_{2} \mathrm{O}$. The

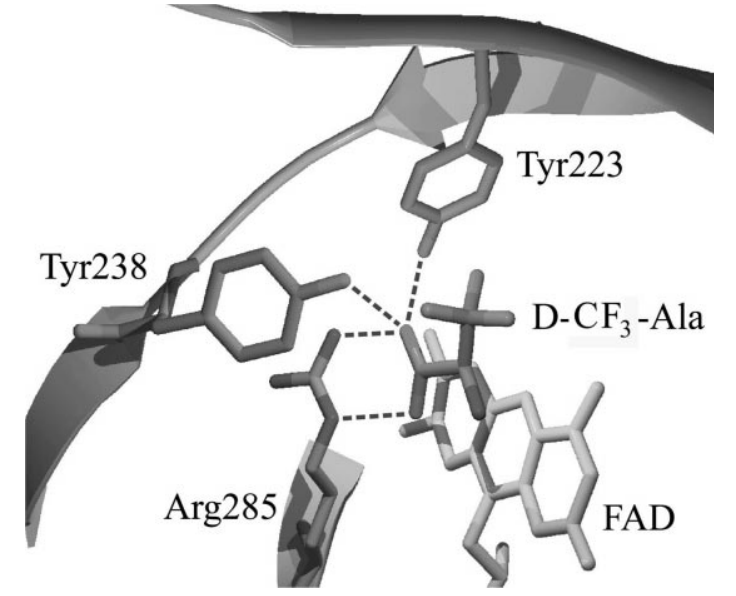

Fig. 1. Active site of $\mathrm{RgDAAO}$ complexed with $\mathrm{CF}_{3}$-alanine (accession code $1 \mathrm{c} 0 \mathrm{p})$.

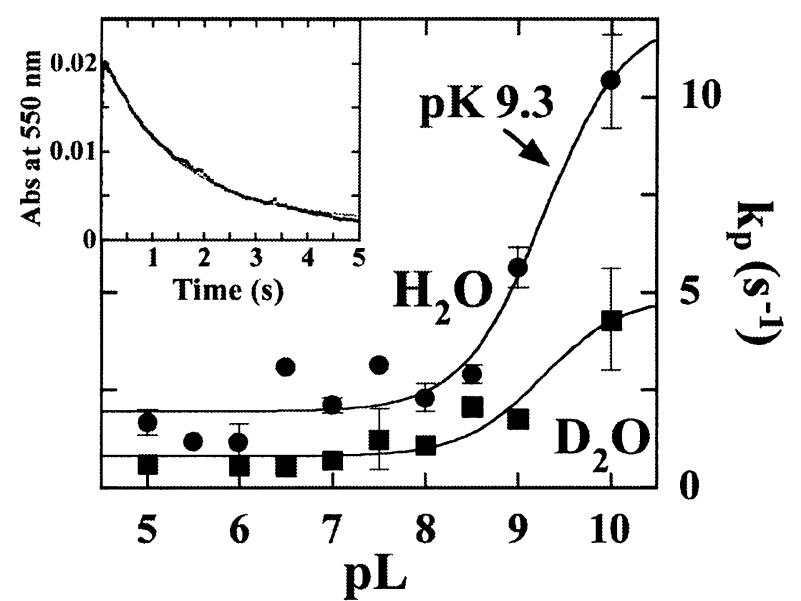

Fig. 2. $\mathrm{pL}(\mathrm{L}=\mathrm{H}, \mathrm{D})$ dependence of the rate of product dissociation from reduced enzyme $\left(k_{\mathrm{p}}\right.$ in Eq. 3$)$. The rates of the second phase of the anaerobic reaction with D-alanine, from experiments such as depicted in the inset (see also [13]), have been determined in $\mathrm{H}_{2} \mathrm{O}$ $(\bullet)$ and $\mathrm{D}_{2} \mathrm{O}(\boldsymbol{\square})$. The lines through the data points (the average of at least three single measurements) are the fit based on Eq. 2 $\left(R^{2}=0.925\right.$ and 0.955 in $\mathrm{H}_{2} \mathrm{O}$ and $\mathrm{D}_{2} \mathrm{O}$, respectively). The inset shows (dashed line) a representative time course at $550 \mathrm{~nm}$ for the reaction of $8.8 \mu \mathrm{M}$ enzyme with $5 \mathrm{mM}$ D-alanine, in $\mathrm{D}_{2} \mathrm{O}$ and at $\mathrm{pH}$ 8. The line (solid line) is the fit for a two exponential decay process yielding $k_{\mathrm{obs} 1}=70 \mathrm{~s}^{-1}$ (increase in absorbance, corresponding to $k_{2}$ in Eq. 3, formation of intermediate) and $k_{\mathrm{obs} 2}=0.7 \mathrm{~s}^{-1}$ (decrease in absorbance the rate of product release, $k_{\mathrm{p}}$ in Eq. 3).

resulting solvent KIE is constant over the whole $\mathrm{pH}$ range (Fig. 2). Note that the error in the determination of the $\mathrm{p} K_{\mathrm{a}}$ is rather large owing to the instability of the enzyme at $\mathrm{pH}>10$ in experiments requiring extensive manipulations under anaerobic conditions. Thus, the expected $\Delta \mathrm{p} K \sim 0.4$ for $\mathrm{D}_{2} \mathrm{O}$ and $\mathrm{H}_{2} \mathrm{O}$ (due to equilibrium isotope effect of weak acids) cannot be identified and is within the experimental error.

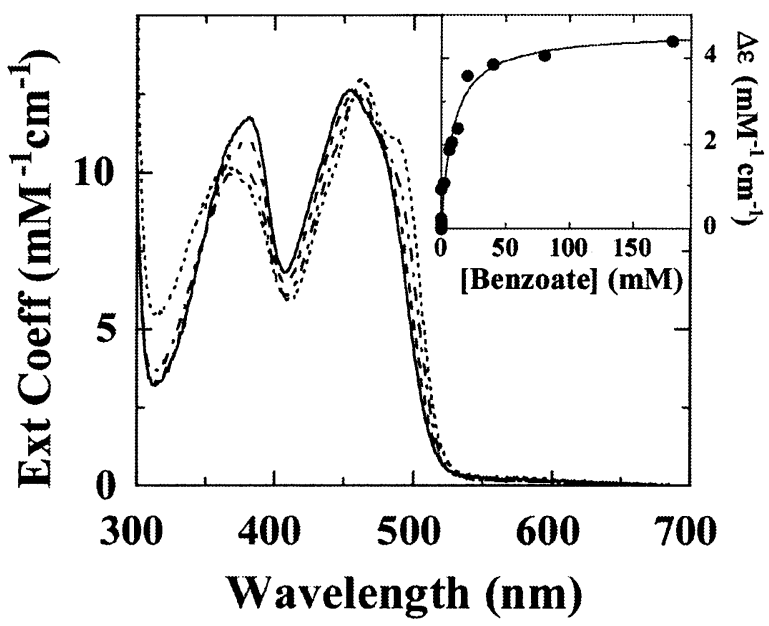

Fig. 3. Effect of $\mathrm{Bz}$ binding on the absorbance spectrum of wildtype RgDAAO at $15^{\circ} \mathrm{C} .20 .0 \mu \mathrm{M}$ DAAO in poly-buffer at $\mathrm{pH} 7.85$ before (solid line) and after the addition of $4.1 \mathrm{mM}$ (dashed line with long dashes), $20 \mathrm{mM}$ (dash-dot dash line), and $80 \mathrm{mM}$ (dashed line with short dashes) $\mathrm{Bz}$. Inset: plot of $\Delta \varepsilon_{497 \mathrm{~nm}}$, the change in extinction coefficient, as a function of $\mathrm{Bz}$. 


\section{2. $B z$ binding}

$\mathrm{Bz}$ is a competitive inhibitor of DAAO, and it binds at the active site inducing typical spectral effects on the flavin chromophore [16,17]. Fig. 3 depicts the effects accompanying binding to RgDAAO at $\mathrm{pH} 7.85$, and the inset demonstrates saturation behavior. The same pattern of spectral changes is observed over the whole $\mathrm{pH}$ range 5.0-10.5. However, the amplitude of the band at $497 \mathrm{~nm}$ shows a $\mathrm{pH}$ dependence $\left(\Delta \varepsilon=4300 \mathrm{M}^{-1} \mathrm{~cm}^{-1}\right.$ at $\mathrm{pH} 5$ and $=3000 \mathrm{M}^{-1} \mathrm{~cm}^{-1}$ at $\mathrm{pH}$ $11)$; the fit of such data to a single ionization [14] allows the estimation of an apparent $\mathrm{p} K_{\mathrm{a}} \sim 9.6 \pm 0.3$ (not shown). A similar apparent $\mathrm{p} K_{\mathrm{a}} \sim 9.8 \pm 0.1$ is reflected by the $\mathrm{pH}$ dependence of $K_{\mathrm{d}}$ for $\mathrm{Bz}$ binding as shown in the double logarithmic plot of Fig. 4. The correspondence between these two $\mathrm{p} K_{\mathrm{a}}$ values strongly suggests that both reflect the ionization of the same group. Analysis according to the rules of Dixon [15] indicates that $\mathrm{Bz}$ binding is decreased upon deprotonation of a group with a $\mathrm{p} K_{\mathrm{a}} \sim 9.8$, while the downward curvature determines that the ionization is of either free enzyme or free ligand. Since the $\mathrm{p} K_{\mathrm{a}}$ of free $\mathrm{Bz}$ is 4.2 , we can assign this ionization to an uncomplexed enzyme. The slope of the fitted curve approaches -1 at high $\mathrm{pH}$, equivalent to a net change of one charge concomitant with ligand association [15]. This is consistent with the existence of a single ionizing residue that must be protonated for optimal $\mathrm{Bz}$ binding. The same experimental data may also be fit using a two ionizations equation. The same experimental data may also be fit using an equation based on two ionizations. The lower limit of the second ionization $\left(>11.3\right.$ ), which would correspond to the $\mathrm{p} K_{\mathrm{a}}$ of $\mathrm{Bz}-$ complexed enzyme (not shown), is above the $\mathrm{pH}$ at which the enzyme is stable and did not give a better fitting. However, the quality of the data is low at $\mathrm{pH}>11$ due to the instability of the protein and to interference with spectral changes associated with the ionization of the flavin $\mathrm{N}(3)-\mathrm{H}\left(\mathrm{p} K_{\mathrm{a}} \sim 10.5\right.$ [3]). The rate of $\mathrm{Bz}$ binding to $\mathrm{RgDAAO}$ is too fast to be assessed with the stopped-flow instrument. This contrasts with the case of pkDAAO where binding is relatively slow with a rate constant $3 \times 10^{5} \mathrm{M}^{-1} \mathrm{~s}^{-1}$ at $\mathrm{pH} 8.0[16,18]$.

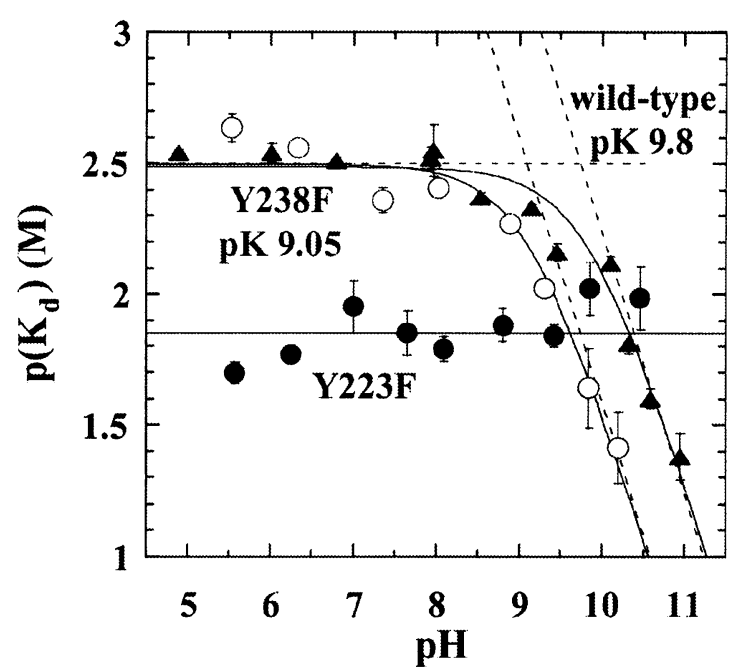

Fig. 4. $\mathrm{pH}$ dependence of $\mathrm{Bz}$ binding. The $\mathrm{p} K_{\mathrm{d}}$ for binding of $\mathrm{Bz}$ to

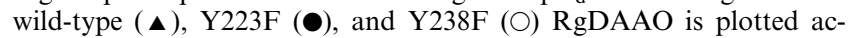
cording to Dixon [15]. Fits to Eq. 2 yield a $\mathrm{p} K_{\mathrm{d} \text {, acidic }} 2.5$ for wildtype and Y238F-DAAOs. Data for Y223F were fit to a linear function with a slope $=0$ and a $\mathrm{p} K_{\mathrm{d}}=1.84$. The segments (dashed lines) indicate the theoretical slopes of 0 or -1 .

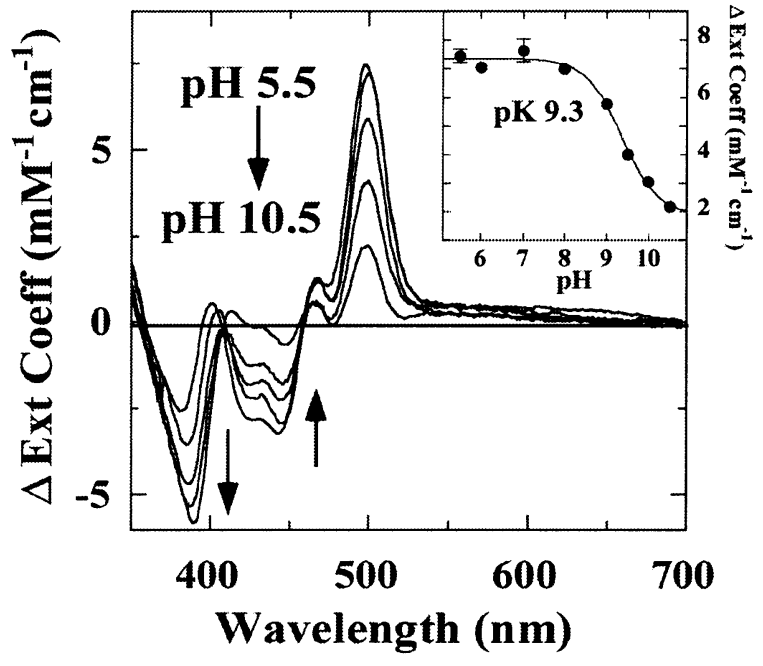

Fig. 5. Difference spectra for $\mathrm{Bz}$ binding to $\mathrm{Y} 238 \mathrm{~F}-\mathrm{DAAO}$ in the $\mathrm{pH}$ range 5.5-10.5. Traces were obtained by subtraction of the absorbance spectrum of the free oxidized RgDAAO from the spectrum of the same enzyme after addition of saturating Bz. The traces are (top to bottom curves at $497 \mathrm{~nm}$ ) for $\mathrm{pH} 5.5,8.0,9.0,9.5$, and 10.5. Inset: $\mathrm{pH}$ dependence of extinction coefficient at $497 \mathrm{~nm}$ for the Y238F-DAAO-Bz complex. The solid line is the theoretical curve obtained for a single ionization [14] and a $\Delta \varepsilon_{\mathrm{E}-\mathrm{L}(\mathrm{H})}=7370$ $\mathrm{M}^{-1} \mathrm{~cm}^{-1}$ and a $\Delta \varepsilon_{\mathrm{E}-\mathrm{L}(-)}=1880 \mathrm{M}^{-1} \mathrm{~cm}^{-1}$.

In order to assess the role of the active site residues Y223 and Y238 of RgDAAO in ligand binding, the study of the $\mathrm{pH}$ dependence of $\mathrm{Bz}$ binding was extended to the corresponding phenylalanine mutants. The spectral effects observed for Y238F-RgDAAO follow the same pattern found with wildtype enzyme (difference spectra, Fig. 5), with the distinction that the derived $\mathrm{p} K_{\mathrm{a}}$ (fit to Eq. 2) is lowered to $9.1 \pm 0.1$ (Fig. 4). The main difference between the two DAAO variants is represented by the amplitude of the perturbation at $450 \mathrm{~nm}$ induced by $\mathrm{Bz}$ binding at low $\mathrm{pH}\left(\sim 4000 \mathrm{M}^{-1} \mathrm{~cm}^{-1}\right.$ and $\sim 7400 \mathrm{M}^{-1} \mathrm{~cm}^{-1}$ for wild-type and Y238F-DAAO). This indicates that the mode of binding of $\mathrm{Bz}$ is retained in the mutant, and that the effects can be attributed to an altered polarity of the active site. The pattern of the difference spectra observed with RgDAAO is also quite similar to that reported for pkDAAO at $\mathrm{pH} 8.5$ [16]. The inset of Fig. 5 depicts the $\mathrm{pH}$ dependence of the molar absorption coefficients at $497 \mathrm{~nm}$ for the Y238F-DAAO-Bz complex in the range $\mathrm{pH}$ 5.5-10.5. The solid line is the fit for a single ionization [14] and identifies a $\mathrm{p} K_{\mathrm{a}}$ of $9.3 \pm 0.1$, very close to the value $\sim 9.05 \mathrm{ob}-$ tained from the $\mathrm{pH}$ dependence of $K_{\mathrm{d}} \mathrm{s}$ (see above and Fig. 4). $\mathrm{Bz}$ binding to $\mathrm{Y} 223 \mathrm{~F}$ is weaker and essentially independent of $\mathrm{pH}$, with a $K_{\mathrm{d}} \sim 15 \mathrm{mM}$ (Fig. 4). Also, and in contrast to binding to wild-type and Y238F-RgDAAOs, the induced absorbance changes are less pronounced than those with the Y238F mutant and little dependent on $\mathrm{pH}$ at $\sim 500 \mathrm{~nm}$ $\left(\Delta \varepsilon \sim 3000 \pm 750 \mathrm{M}^{-1} \mathrm{~cm}^{-1}\right.$ at $\left.\mathrm{pH} 5.5-10.5\right)$. These results identify Y223 as the group with a $\mathrm{p} K_{\mathrm{a}}=9.8 \pm 0.1$ whose deprotonation weakens $\mathrm{Bz}$ binding.

\section{3. $\mathrm{CF}_{3}$-alanine binding}

The salient feature of $\mathrm{D}-\mathrm{CF}_{3}$-alanine is that it is nearly isosteric with the substrate D-alanine, while it has a much lower $\mathrm{p} K_{\mathrm{a}}$ of the $\alpha \mathrm{NH}_{2}$ group ( $\sim 5.85$ vs. 9.69 for alanine) and is not a substrate [5] due to its high redox potential. Since 


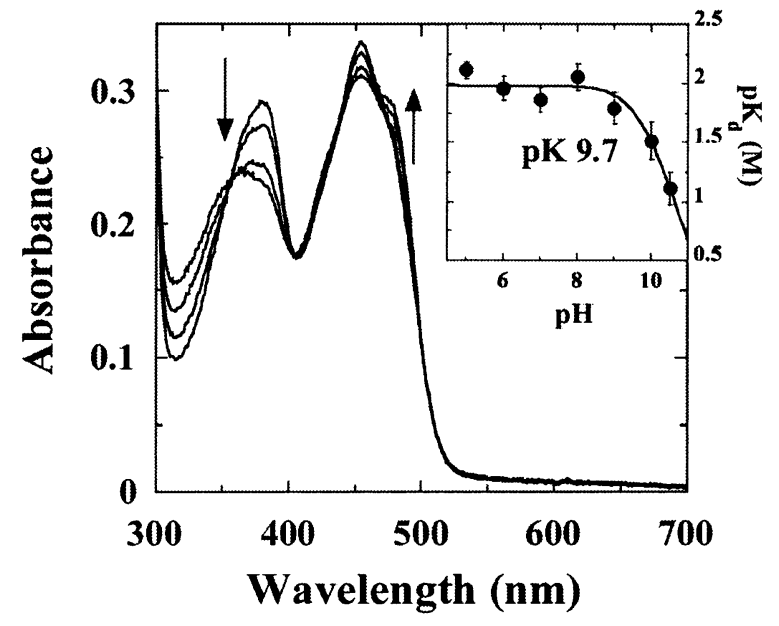

Fig. 6. Interaction of wild-type $\mathrm{RgDAAO}$ with $\mathrm{CF}_{3}$-alanine and its $\mathrm{pH}$ dependence. The absorption spectrum is shown for $24.8 \mu \mathrm{M}$ RgDAAO at $\mathrm{pH} 7.0$ and $15^{\circ} \mathrm{C}$, and upon addition of $3.0 \mathrm{mM}, 13.5$ $\mathrm{mM}$, and $26 \mathrm{mM} \mathrm{D}-\mathrm{CF}_{3}$-alanine. The arrows denote the changes with increasing ligand concentration. Inset: $\mathrm{pH}$ dependence of $\mathrm{p} K_{\mathrm{d}}$ plotted according to Dixon [15]. The curve was generated using Eq. 2 and $\mathrm{a} \mathrm{p} K_{\mathrm{d} \text {, acidic }}=1.9\left(R^{2}=0.942\right)$.

RgDAAO is not inhibited by L-amino acids [2,3], use of racemic $\mathrm{CF}_{3}$-alanine causes no complications. Addition of $\mathrm{CF}_{3}$ alanine to wild-type RgDAAO causes a spectral perturbation similar to that induced by other ligands of DAAO (Fig. 6). At difference with that previously observed for $\mathrm{Bz}$ binding to wild-type DAAO, the absorbance changes do not show a clear $\mathrm{pH}$ dependence (data not shown). $K_{\mathrm{d}}$ for $\mathrm{CF}_{3}$-alanine binding varies $\sim 7$-fold from $\mathrm{pH} 5$ to 11 (Fig. 6, inset), and reflects a $\mathrm{p} K_{\mathrm{a}}=9.7 \pm 0.2$ for the ionization of a single group on free enzyme or ligand (fit to Eq. 2). The ionization in question is thus attributed to Y223.

\section{Discussion}

With pkDAAO, the $\mathrm{pH}$ dependence of $\mathrm{Bz}$ binding reflects three ionizations with $\mathrm{p} K_{\mathrm{a}} \mathrm{s}$ at 6.3, 9.2, and 9.6 [16], where only the latter could be assigned (to the $\mathrm{N}(3)-\mathrm{H}$ group of the flavin). With RgDAAO, a single ionization with a $\mathrm{p} K_{\mathrm{a}} \sim 9.8$ is observed (Fig. 4) that is assigned to Y223. As shown by the $3 \mathrm{D}$ structures, R285 is the anchoring point for ligands (Fig. 1). Based on the structural analogy between RgDAAO and pkDAAO $[5,8,10]$, it can be speculated that the $\mathrm{p} K_{\mathrm{a}} \sim 9.2$ in the latter is also due to either of the active site tyrosines, Y224 or Y228. Assignment of the third $\mathrm{p} K_{\mathrm{a}}$ at 6.3 in pkDAAO remains elusive, although this ionization might correspond to an apparent $\mathrm{p} K_{\mathrm{a}} \sim 6$ recently uncovered with RgDAAO [13]. The $\mathrm{pH}$ dependence of $\mathrm{CF}_{3}$-alanine binding reflecting a $\mathrm{p} K_{\mathrm{a}} \sim 9.7$ (Fig. 6) shows that the effects are not unique to binding of $\mathrm{Bz}$, but are applicable to the binding of amino acids. Y238 affects only marginally the thermodynamics of Bz binding (Fig. 4). Y238 in RgDAAO can assume different positions depending on the size and properties of the ligand (Pollegioni et al., unpublished results). With an- thranilate bound, the side chain of Y238 assumes a different position compared to the complexes with D-alanine and $\mathrm{CF}_{3}$ alanine.

As pointed out previously [2,3], the main difference between yeast and pkDAAOs is the location of the rate limiting step in the catalytic cycle. This is (in general) substrate dehydrogenation with yeast DAAO and product release with pkDAAO. The $\mathrm{pH}$ dependence of the rate constant for product release in $\mathrm{RgDAAO}$ reflects a $\mathrm{p} K_{\mathrm{a} \text {, app }} \sim 9.3$ (Fig. 2). Ionization of Y223-OH, thus, is likely to weaken the interaction with the (product) imino acid carboxylate and to increase its rate of dissociation. This would also be in line with the proposal that, with pkDAAO, product release requires a conformational change that is coupled to the release of a proton $[18,19]$. While a conformational change might also play a role in RgDAAO catalysis (e.g. the rotation of the side chain of Y238), a major factor affecting ligand release should be the deprotonation of a group with an apparent $\mathrm{p} K_{\mathrm{a}} \sim 9.3$ [13] that, from the present results, is proposed to be $\mathrm{Y} 223-\mathrm{OH}$.

\section{References}

[1] Massey, V. and Hemmerich, P. (1980) Biochem. Soc. Trans. 8, 246-257.

[2] Curti, B., Ronchi, S. and Pilone Simonetta, M. (1992) in: Chemistry and Biochemistry of Flavoenzymes (Muller, F., Ed.), pp. 69-94, CRC Press, Boca Raton, FL.

[3] Pilone, M.S. (2000) Cell. Mol. Life Sci. 57, 1732-1747.

[4] Faotto, L., Pollegioni, L., Ceciliani, F., Ronchi, S. and Pilone, M.S. (1995) Biotechnol. Lett. 17, 193-198.

[5] Umhau, S., Pollegioni, L., Molla, G., Diederichs, K., Welte, W., Pilone, M.S. and Ghisla, S. (2000) Proc. Natl. Acad. Sci. USA 97, 12463-12468.

[6] Harris, C.M., Molla, G., Pilone, M.S. and Pollegioni, L. (1999) J. Biol. Chem. 274, 36233-36240.

[7] Molla, G., Harris, C.M., Boselli, A., Sacchi, S., Pilone, M.S. and Pollegioni, L. (1999) in: Flavins and Flavoproteins (Ghisla, S., Kroneck, P., Macheroux, P. and Sund, H., Eds.), pp. 559-562, Weber, Berlin.

[8] Mattevi, A., Vanoni, M.A., Todone, F., Rizzi, M., Teplyakov, A., Coda, A., Bolognesi, M. and Curti, B. (1996) Proc. Natl. Acad. Sci. USA 93, 7496-7501.

[9] Pollegioni, L., Blodig, W. and Ghisla, S. (1997) J. Biol. Chem. $272,4924-4934$.

[10] Mizutani, H., Miyahara, I., Hirotsu, K., Nishina, Y., Shiga, K., Setoyama, C. and Miura, R. (1996) J. Biochem. (Tokyo) 120, 14 17.

[11] Pollegioni, L., Fukui, K. and Massey, V. (1994) J. Biol. Chem. 269, 31666-31673.

[12] Molla, G., Porrini, D., Job, V., Motteran, L., Vegezzi, C., Campaner, S., Pilone, M.S. and Pollegioni, L. (2000) J. Biol. Chem. 275, 24715-24721.

[13] Harris, C.M., Pollegioni, L. and Ghisla, S. (2001) Eur. J. Biochem. 268, 5504-5520.

[14] Fersht, S. (1985) Enzyme Structure and Mechanism, pp. 134-154, W.H. Freeman and Co., New York.

[15] Dixon, M. (1953) Biochem. J. 55, 161-170.

[16] Quay, S. and Massey, V. (1977) Biochemistry 16, 3348-3354.

[17] Pilone Simonetta, M., Pollegioni, L., Casalin, P., Curti, B. and Ronchi, S. (1989) Eur. J. Biochem. 180, 199-204.

[18] Fitzpatrick, P.F. and Massey, V. (1982) J. Biol. Chem. 257, 9958-9962.

[19] Denu, J.M. and Fitzpatrick, P.F. (1994) J. Biol. Chem. 269, 15054-15059. 